\title{
HOMOAFETIVIDADE E LITERATURA NA AMÉRICA LATINA: DOIS ESCRITORES, DUAS VIDAS, NARRATIVAS...
}

Flávia Péret

Mestre em Letras: Estudos Literários - UFMG

\begin{abstract}
RESUMO
O artigo aborda aspectos da vida e das obras dos escritores Manuel Puig (Argentina) e Pedro Lemebel (Chile), evidenciando como esses autores criaram em suas respectivas narrativas uma intensa interseção entre vida e literatura.
\end{abstract}

\section{PALAVRAS-CHAVE}

Manuel Puig, Pedro Lemebel, literatura, América Latina, homoafetividade

Desde sua consolidação, no século 18, a literatura nos ajuda a compreender a sexualidade humana. Seja para torná-la mais clara ou para revelar aspectos sombrios e misteriosos de sua constituição - o sexo, a sexualidade e o desejo sempre estiveram presentes na literatura universal. Nesse espaço de tempo o mundo modificou-se. A época atual, definida por alguns teóricos como a pós-modernidade, ${ }^{1}$ impôs uma reconfiguração radical das sexualidades. Os papéis tradicionais do feminino e do masculino também foram alterados, apontando novas direções para a construção das identidades sexuais. A literatura como experiência estética e social acompanhou tais mudanças e apresenta narrativas que colocam sob suspeita nossas concepções e opiniões sobre a sexualidade humana. Vivemos, como afirma a feminista norte-americana Judith Butler, ${ }^{2}$ uma era pós-gênero, ou seja, um período no qual as definições históricas, culturais e, principalmente, sociais das disponibilidades genéricas

\footnotetext{
${ }^{1}$ A ideia de pós-modernidade surgiu na segunda metade do século 20, com a consolidação da indústria cultural e da sociedade de consumo. Para os historiadores é o processo segundo o qual todas as instâncias da vida dos indivíduos (política, filosófica, moral, econômica, etc.) são revistas e reconfiguradas. Como consequência ideológica e discursiva da pósmodernidade, surgem a contracultura, o femininos e outros movimentos.

2 Pós-feminista norte-americana que indaga em suas obras a construção do gênero e da identidade feminina, criticando os valores da tradição feminista.
} 
(feminino/masculino), dão lugar a gêneros múltiplos e performativos, gêneros emergentes que reivindicam possibilidades mais plurais de significação e expressão.

A experiência de vida e a denúncia da violência impingida contra os indivíduos que deslocam o desejo do seu lugar convencional e apresentam formas de amar não hegemônicas são temas que estão presentes na literatura latino-americana desde o século 19. Porém, tanto no Brasil quanto nos demais países do continente sulamericano, foi a partir de 1970 que uma produção efetivamente comprometida com a temática e as demandas das minorias sexuais se consolidou. Esse período marca a emergência de um conjunto de escritores que desestrutura os alicerces literários de culturas nacionais extremamente patriarcas, católicas e homofóbicas.

É nessa perspectiva, de ampliação das fronteiras identitárias, que deslocamos nosso olhar para a obra de dois importantes escritores latino-americanos: Manuel Puig (1932-1990, Argentina) e Pedro Lemebel (Chile, 1952). Embora tenham iniciado suas carreiras em décadas distintas, ambos desenvolveram e desenvolvem, no caso de Lemebel, um trabalho consistente de desconstrução e reconstrução do imaginário sexual, apresentando, de forma inédita, uma gama de nuances, personagens e narrativas que colocaram em primeiro plano as relações homoeróticas e suas articulações com a literatura, o poder, a moral, a religião e a política.

Ao analisar a vida e a obra desses dois autores, observamos como o surgimento da temática homoerótica em suas respectivas narrativas revela um modo particular de escrita. Uma narrativa intimamente ligada à vivência sexual e que dá relevo a experiências afetivas e sexuais que enunciam e tratam das formas de desejo não hegemônicos, formas estas, historicamente, relegadas ao segundo plano na produção literária do continente.

A escrita de Manuel Puig e Pedro Lemebel apresenta algumas semelhanças significativas do ponto de vista formal e estético, principalmente no que tange às subversões que os escritores impõem ao texto literário. Nesse sentido, é inegável a percepção de elementos literários que materializam o que chamamos de "uma escrita de si”, fundada na experiência do sujeito/autor e que dialoga (conscientemente ou não) com a experiência coletiva da marginalização sexual. 


\section{MANUEL PUIG: SEXO, PODER E POLÍTICA}

Manuel Puig foi um dos primeiros escritores latino-americanos a abordar tão explicitamente em suas obras a temática e o universo homossexual. Entre seus livros mais conhecidos estão: A traição de Rita Harworht (1968), Boquitas pintadas (1969), The Buenos Aires affair (1973) e O beijo da Mulher Aranha (1976). Iconoclasta, melodramático, pop, vanguardista e pós-moderno, vários foram os adjetivos que os críticos utilizaram para “classificar” o texto puiguiano. De forma inédita, ele se apropriava de discursos extraliterários como trechos de diários, cartas, recortes de jornais e boletins policiais para construir uma narrativa polifônica e intertextual. Ao criar uma nova forma de fazer literatura - criando esse intenso diálogo ou teia intertextual -, Puig subverteu radicalmente o cânone literário Argentino, país que tem como base de sua tradição literária escritores como Jorge Luis Borges e Júlio Cortázar.

A fórmula do melodrama policial inventada por Manuel Puig baseava-se na utilização do excesso da indústria cultural - filmes hollywodianos, tangos, boleros, revistas de moda e rádio-novelas - como matéria textual para suas narrativas. A questão do sujeito pós-moderno, imerso em relações superficiais e frívolas, que encontra escape no cinema e nos folhetins, é um tema presente já no seu primeiro romance, A traição de Rita Harworht.

Silviano Santiago, no texto "Manuel Puig - a atualidade do precursor”, destaca que o ineditismo do texto puiguiano constituía-se especialmente na utilização dos excessos (ou lixo) da indústria cultural. "Manuel Puig é o primeiro grande autor latinoamericano que trabalha com a forma de escombro derivada do excesso da indústria cultural estadunidense e Argentina, ou seja com o quase lixo - filmes ultra-sentimentais, rádio novelas, tangos e boleros.”3

A produção da indústria cultural, sobretudo o cinema norte-americano, que fascinou Manuel Puig durante toda à vida , era a principal matéria-prima desse autor, assumidamente homossexual, e que, em função dos livros que escreveu e do seu “comportamento” sexual, foi proibido, durante alguns anos, de viver na Argentina. A orientação sexual do escritor, somada à revolução que impôs à literatura, subvertendo a linha que separa a "alta” cultura da cultura de "massa”, são alguns dos fatores que

\footnotetext{
${ }^{3}$ SANTIAGO. O cosmopolitismo do pobre, p. 370.
} 
explicam a resistência da crítica especializada Argentina em respaldar a literatura de Manuel Puig.

A fragmentação, a montagem, a ausência de narrador (...) a alteração do ordenamento de materiais segundo dicotomias culturais que oscilavam do alto ao baixo, do sério ao trivial, do legítimo ao popular, do literário ao cinematográfico/midiático. (...) a paixão pelos objetos degradados, a abolição da autonomia do privado, a sublimação da cópia e o simulacro. ${ }^{4^{3}}$

Segundo a pesquisadora Veridiana Nogueira da Gama, a "opoisção entre estrutura e colagem” era um dos principais recursos literários desse autor, que também criava mecanismos de representação da alteridade sexual em suas obras, como uma espécie de espelho dos dilemas vivenciados pelas minorias sexuais em seu país.

No entanto, mesmo com a ótima recepção da crítica internacional e os convites para ser traduzido e publicado em outros países - A traição de Rita Hayworth integrou a lista dos dez melhores livros publicados na França em 1969 -, o autor era uma figura inexistente nos meios culturais argentinos.

A crônica "Manuel: la muerte no es un adiós", escrita por Tomaz Eloy Martinez, amigo íntimo de Puig e publicada em 1997 no jornal La Nación, revela a decepção vivenciada pelo escritor, em função do fato de não ser aceito e compreendido em seu próprio país.

En 1973, cuando publicó The Buenos Aires affair y le llovián las ofertas para traducirlo, empezó a sentir que la Argentina no le hacía justicia. Había llegado más lejos que cualquier otro escritor de su generación, pero se lo trataba como a uno cualquiera. No quería aceptar que el país siempre habiá sido así, y que seguiría siéndolo. Cuando recuerdo los encuentros de aquellos años me parece volver a oír su inagotable amargura. Suponía que los críticos argentinos -tanto en los medios de prensa como en la universidad- consideraban su obra como un artificio menor, destinado a no perdurar, sino a ser consumido e olvidado por el mercado. ${ }^{5}$

\footnotetext{
${ }^{4}$ NOGUEIRA DA GAMA. Manuel Puig e Wong Kar Wai: os imbricamentos do Kitsch e da memória, p. 43.

${ }^{5}$ MARTINEZ. Manuel: la muerte no es un adiós. "Em 1973, quando publicou The Buenos Aires affair e choviam ofertas para traduzi-lo, começou a sentir que a Argentina não lhe fazia justiça. Havia chegado mais longe que qualquer outro escritor de sua geração, mas o tratavam como um qualquer. Não queira aceitar que o país havia sido assim, e que seguiria sendo. Quando recordo os encontros daqueles anos, sinto que posso voltar a ouvir sua inesgotável amargura. Supunha que os críticos argentinos - tanto da imprensa quanto da universidade - consideravam sua obra um artifício menor, destinado a não perdurar e sim a ser consumido e esquecido pelo mercado.” (<http://www.literatura.org/TEMartinez/mpuig.html>.) (tradução nossa)
} 
No entanto, o tempo mostrou que a crítica especializada estava equivocada. Manuel Puig é hoje um ícone da literatura argentina contemporânea; seus livros foram traduzidos para mais de 20 línguas e várias obras adaptadas para o cinema e também para o teatro. Porém, é significativo observar que o estilo criado pelo autor, especialmente a interseção que realizava entre os termos sexo, poder, política e indústria cultural, resultava em uma equação perigosa, quase explosiva para a cultura Argentina da época, uma sociedade extremamente católica, patriarcal e antidemocrática.

Se, desde a publicação do primeiro romance, Puig havia criado um mal-estar ao criar personagens nitidamente superficiais e provocativas, brincando livremente com as palavras "folhetim” e "romance policial” nos subtítulos de seus romances e realizando uma forte crítica aos costumes da classe média local, foi com a publicação de $O$ beijo da Mulher Aranha (1976) e a representação que fez da homossexualidade nesse livro que Manuel Puig passou a ser não apenas um escritor invisível e “inconveniente”, mas alvo de severas críticas.

A perseguição a Puig se deve ao fato desse livro abordar de maneira contundente alguns temas tabu na Argentina e na América Latina, do período: a homossexualidade e a resistência/guerrilha política. O beijo da Mulher Aranha narra a história de dois homens que dividem a mesma cela numa prisão na cidade de Buenos Aires. Molina (homossexual) e Valentin (preso político), personagens pseudoantagônicos, representam a síntese daquilo que o Estado e a "sociedade” Argentina queriam esconder e punir.

Em 1986, após o lançamento mundial do filme O beijo da Mulher Aranha (1985), levado ao cinema pelo diretor argentino Hector Babenco, Puig é entrevistado pela revista Argentina Crisis. ${ }^{6}$ Na conversa, ele fala abertamente sobre suas concepções sobre a homossexualidade e o movimento gay:

Me parece que la película puede ser una metáfora de lo que yo pienso de la homosexualidad. Para mí, la homosexualidad no existe, es una proyección de la mente reaccionaria. Quiero decir: hay personas que realizan actos homosexuales, pero sería necesario entender que el sexo no tiene trascendencia, no tiene peso moral. El sexo es como comer, beber, dormir, forma parte de la vida vegetativa y por esto es que no me parece que la identidad deba pasar a través de la sexualidad. La idea de dar un peso moral al sexo es un crimen cometido hace muchos siglos, se dice que fue un patriarca el que concibió esta monstruosidad para controlar a las mujeres.

\footnotetext{
${ }^{6}$ Revista argentina, editada na década de 1970, que tratava de política e das artes. Disponível em: <http://www.literatura.org/Puig/repo_puig.html>.
} 
- ¿Entonces usted tampoco cree en la identidad gay, en la cultura gay?

- Yo admiro mucho a los movimientos de liberación gay pero creo en la integración y pienso que hay que hacer una propuesta más radical: negar el sexo como signo de identidad. Yo he tenido conflictos muy graves con la cultura gay, pero creo que es un hecho necesario porque estamos en un estado de transición. Por otra parte, mi crítica más amarga es que en Estados Unidos a las minorías se las calma así, formando un gueto. $\mathrm{Y}$ es el gueto lo que a mí no me parece bien. Cuando la película se presentó en Cannes suscitó polémicas irritadas entre algunos críticos sudamericanos molestos por lo que definían como una imagen sin matices del joven revolucionario. En la película, en efecto, Molina es asesinado por los compañeros de Valentín y ese gesto parece una verdadera crueldad, una prueba de falta de humanidad. También en el libro Molina es asesinado por los revolucionarios, pero es él el que lo pide antes de que la policía descubra la cita, porque sabe que si lo meten preso no va a tener la fuerza de no hablar y así es que prefiere morir. quedar limpio a los ojos de la persona amada, en un sentido romántico y muy femenino ¿no? Porque antes que nada, para él está el rol que se ha elegido en la vida. Por lo demás, toda la novela es una reflexión sobre los roles; los dos personajes están oprimidos, prisioneros de los roles, y lo interesante es que en un cierto momento logran huir de los personajes que se han impuesto. Pero no es que superen todos los límites; Molina queda como la heroína romántica que elige la muerte bella, el sacrificio por el hombre amado. ${ }^{7}$

7 "Eu acho que o filme pode ser uma metáfora do que eu penso sobre a homossexualidade. Para mim, a homossexualidade não existe, é uma projeção da mente reacionária. Quero dizer: existem pessoas que realizam atos homossexuais, mas seria necessário entender que o sexo não tem transcendência, não tem peso moral. O sexo é como comer, beber, dormir, faz parte da vida vegetativa e por isso é que penso que a identidade não deve passar através da sexualidade. A ideia de dar um peso moral ao sexo é um crime cometido há muitos séculos, dizem que foi um patriarca que concebeu essa monstruosidade para controlar as mulheres.

- Então o senhor também não acredita na identidade gay, na cultura gay?

Eu admiro muitos os movimentos de liberação gay, mas acredito na integração e penso que deve ser feita uma proposta mais radical: negar o sexo como signo de identidade. Eu tive conflitos graves com a cultura gay, mas acredito que é um fato necessário porque estamos em um estado de transição. Por outra parte, minha crítica mais amarga é que nos Estados Unidos acalmam-se as minorias formando um gueto. E é o gueto o que não acho bom. Quando o filme foi apresentado em Cannes suscitou polêmicas irritadas entre alguns críticos sulamericanos incomodados com o que eles chamam de uma imagem sem matizes do jovem revolucionário. No filme, na realidade, Molina é assassinado pelos companheiros de Valentin e esse gesto parece uma verdadeira crueldade, uma prova de falta de humanidade. Também no livro, Molina é assassinado por revolucionários, mas é ele que pede antes que a polícia descubra o encontro, porque sabe que se for preso não teria a força de não falar e assim é que prefere morrer, ficar limpo aos olhos da pessoa amada, em um sentido, muito romântico e feminino, não? Porque antes de tudo está o papel que ele escolheu para sua vida. No mais, todo romance é uma reflexão sobre os papéis, as personagens estão oprimidas, prisioneiras desses papéis, e o interessante é que em um certo momento conseguem fugir dos personagens que se impuseram. Mas não é que superam todos os limites: Molina fica como a heroína romântica que escolhe a bela morte, o sacrifício para o homem amado.” (tradução nossa) 
Embora a fala de Puig aponte para uma direção (a da não guetificação, e sim de uma abertura), é interessante observar que a escrita homoerótica do autor emerge, simultaneamente, aos diversos movimentos identitários e culturais que ele crítica na entrevista. Mesmo que não compartilhe ideologicamente as estratégias adotadas pelo movimento gay, o texto puiguiano estabeleceu uma marca indelével na literatura de temática homoerótica latino-americana: a diluição dos gêneros sexuais e a relativização do conceito de homossexualidade, que passa a ser apresentado como algo movente e fluido e não mais fixo e inquestionável.

No livro O beijo da mulher aranha, quando os personagens Valentin e Molina dormem juntos e se beijam, a imagem tabu presente no imaginário coletivo latinoamericano - “macho” versus "bicha” - é rompida e, definitivamente, questionada, já que ela expressa a existência das múltiplas possibilidades de o indivíduo vivenciar sua sexualidade e seus afetos.

\section{PEDRO LEMEBEL: SEXUALIDADE VERSUS POLÍTICA}

Manuel Puig influenciou uma geração de escritores latino-americanos como o chileno Pedro Lemebel. Herdeiro do estilo narrativo criado por Puig, o escritor chileno Pedro Lemebel é, ainda, uma figura marginal na literatura latino-americana contemporânea. Os limites geográficos e culturais e a inexistência de traduções, especialmente para o português, dificultam o acesso a esse escritor que, desde a década de 1980, vem revolucionando o cenário artístico chileno. Com uma produção que transita entre as mais diversas manifestações e linguagens, como o vídeo, a fotografia, o conto, as crônicas e a performance (incluindo a travestismo), Pedro Lemebel foi um dos primeiros cidadãos chilenos a declarar publicamente sua homossexualidade.

É significativo fazer um pequeno parênteses para situar historicamente o momento em que Lemebel “emerge” na cena cultural do seu país. Desde 1973, com o golpe militar, um dos mais brutais da América Latina, o Chile vivenciava uma forte ditadura, na qual centenas de pessoas - artistas, jornalistas, intelectuais e professores universitários - foram presas, torturadas e assassinadas. Alguns conseguiram fugir, exilando-se em outros países. A ditadura do general Pinochet foi a última a cair em nosso continente. Por mais de 17 anos, os chilenos viveram sob o terror da perseguição política e da censura artística e ideológica. 
É nesse período de controle irrestrito que Pedro Lemebel inicia sua carreira, promovendo e instigando, com suas intervenções performáticas, um embate provocativo com o regime militar, os direitos humanos, a política e, sobretudo, a sexualidade. Em 1982, Lemebel é vencedor do Concurso Nacional del Cuento Javier Carrerra, e em 1986, lança o primeiro livro de relatos Los incontables. No entanto, é a partir de 1987 que o artista inicia um trabalho sistemático de demolição dos mitos e discursos institucionais da cultura chilena, quando cria, com o amigo Francisco Casas, o coletivo de arte "Yeguas del Apocalipisis". 8

O grupo realizava performances que misturavam a paródia e o tom burlesco a um forte conteúdo político. As apresentações/experimentações, segundo depoimentos do próprio Lemebel, ${ }^{9}$ tinham como objetivo criar uma espécie de escândalo público, borrando os discursos institucionais e reivindicando a emergência de novas enunciações, falas e manifestações artísticas. As performances eram “pautadas” pelo resgate da memória dos Anos de Chumbo, pela subversão da produção literária e cultural e, principalmente, pela discussão dos gêneros e papéis sexuais.

Um texto representativo do trabalho de demolição e ativismo político levado a cabo por Lemebel é o “Manifesto: Hablo por mi diferencia”, publicado no livro de crônicas Loco Afán - crónicas de um Sidario (1997). Na narrativa/manifesto, que foi lida pela primeira vez em um ato realizado pela esquerda chilena, em 1986, Lemebel reivindica o direito à diferença e o respeito à homossexualidade.

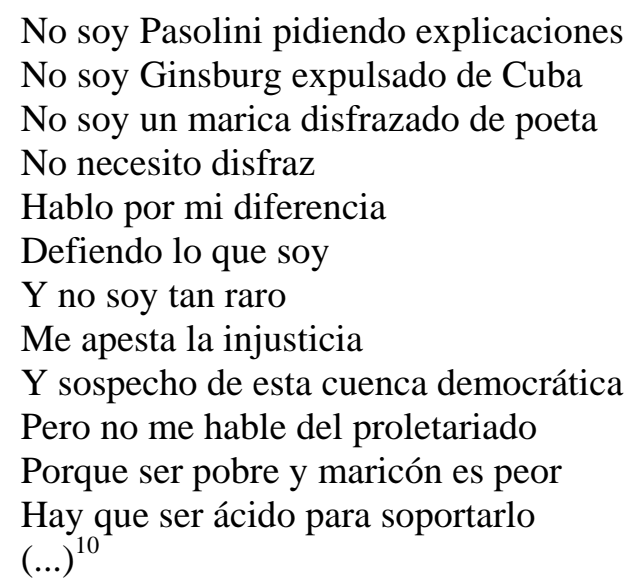

\footnotetext{
8 “Éguas do Apocalipse”

${ }^{9}$ Disponível em: <http://www.letras.s5.com/lemebel1.htm>.

${ }^{10}$ LEMEBEL. Loco Afán - crónicas de um Sidario, p. 83. "Não sou Pasolini fanatasiado de poeta/Não necessito de disfarce/Falo por minha diferenaça/Defendo o que sou/E não sou tão raro/Me da nojo a injustiça/E suspeito desta cuenca* democrática/Mas, não me fale do
} 
Por essas e outras atividades performáticas, Lemebel sempre causou certo malestar dentro do Partido Comunista chileno. Para os militantes de esquerda, homossexualidade e política eram atividades incompatíveis, um discurso extremamente conservador se pensarmos nas políticas de identidade surgidas na década de 1970 . Nesse período, o corpo e a sexualidade passam a fazer parte da agenda política de grupos de mulheres, estudantes, negros e homossexuais. No entanto, a esquerda ordotoxa se mantinha fechada à revolução sexual que os movimentos contraculturais implementaram, a partir de 1960, nos Estados Undios e na Europa e, com alguns anos de atraso, na América Latina.

No que tange ao campo literário, a produção do escritor Pedro Lemebel também perfaz as mais diversas linguagens: do manifesto político, aos contos, e crônicas ${ }^{11}$ gênero que permitiu uma pequena, porém significativa popularização da sua obra no país. Lemebel é inventor de um estilo literário particular: ácido, sarcástico, ferino, ele é avesso à cordialidade, e não mede críticas: do moralismo pequeno-burguês e extremamente católico dos chilenos à própria comunidade gay, que se "fecha" em clubes e boates, mantendo-se afastada das questões políticas.

Os temas Aids, homossexualidade, homofobia e violência são conteúdos recorrentes em suas crônicas. Além de incorporar as referências da cultura pop (chilena e estrangeira), o autor usa a linguagem, os modos de falar, as gírias e jargões de grupos sociais marginalizados (como os gays, travestis e garotos que vivem na periferia de Santiago) para criar um texto que, como afirma a pesquisadora Juliana Leal, confere verossimilhança e polivalência discursiva aos seus "personagens": "Uma obra polivalente, resultado da conflituosa, porém harmoniosa, interseção de elementos literários e não-literários e pela interseção de signos semióticos polifonicamente são construídos. ${ }^{12}$

Segundo Leal, Pedro Lemebel desenvolve em seu trabalho inúmeras espacialidades que interagem e se comunicam, sendo que o literário (ou o

proletariado/Porque ser pobre e bicha é pior/Tem que ser ácido para suportá-lo (...).” *“Cueca” é uma dança folclórica chilena.

${ }^{11}$ Destacamos os livros La esquina es mi corazón (1995), Loco Afán - crónicas de um Sidario (1997) e De Perlas y cicatrices (1995). Durante alguns anos, Lemebel participa semanalmente do programa Cancioneiro, transmitido pela Radio Tierra, no qual lia suas crônicas.

12 LEAL. La esquina es mí corazón: espacialidades performáticas nas crônicas de Pedro Lemebel, p. 11. 
artístico/performático) sempre se coloca a serviço da denúncia e da restituição da memória. Nesse sentido, sua obra é crucial para compreendermos como a produção artística - sitiada em um ambiente de censura e silenciamento como o Chile de Pinochet - pode insurgir, simultaneamente, contra as duas principais formas de opressão e regulação social dos indivíduos: sob seus corpos (a questão da sexualidade e da identidade) e sob seus pensamentos (a questão da política e da ideologia).

Em Loco Afán - crónicas de um Sidario, Lemebel reúne um conjunto de textos que trata, em sua maioria, de um mesmo tema: o terror e o drama decorrente do vírus HIV. Os personagens sãos gays, artistas e, principalmente, travestis - um dos primeiros grupos sociais, segundo Lemebel, a sofrer as consequências da Aids. Ao longo das 29 crônicas presentes no livro, separadas em blocos temáticos, cinco textos abordam diretamente histórias de vida de travestis. Relatos que, ao serem "transferidas” para o papel, se ficcionalizam, ganhando matizes, olhares e expressões discursivas próprias da escrita de Pedro Lemebel.

A impressão que temos ao ler suas crônicas é que, ao contrário do escritor Manuel Puig, que em muitos textos edulcoram a realidade, submergindo os leitores em um universo onírico de fantasias e ficção, o escritor chileno trabalha obsessivamente com a matéria bruta do cotidiano, das páginas policiais e do submundo callejero $^{13}$ da cidade de Santiago. Uma investigação minuciosa, ferina e, às vezes cruel, dos aspectos mais sórdidos do comportamento humano. No entanto, é justamente a partir desse material de "segunda categoria" que podemos ter contato com a alteridade e com a diferença, compreendendo e penetrando em modos de vida, pensar e agir, aparentemente distantes da vida diurna dos cidadãos de bem.

Esse aspecto [a valorização da alteridade] se configura como uma característica de destaque em seus textos, na medida em que o eu literário, aparentemente solitário, funciona como uma espécie de sujeito enunciador dos desejos, protestos, denúncias e indignações de múltiplos sujeitos. Discurso coletivo que põe em ênfase a realidade de indivíduos cujas identidades foram e são fragmentadas pelos efeitos repressores de sistemas ditatoriais ou por sistemas econômicos sociais excludentes e estigmatizantes. ${ }^{14}$

A homossexualidade, na América Latina, representa o outro lado de uma sociedade baseada no catolicismo e no machismo. Muitas pessoas creem que a

\footnotetext{
${ }^{13}$ [De rua].

${ }^{14}$ LEAL. La esquina es mí corazón: espacialidades performáticas nas crônicas de Pedro Lemebel, p. 13.
} 
indiferença é a atitude conveniente, como se a encenada apatia tornasse o outro, no caso os homossexuais, invisíveis. Lemebel nos mostra o contrário: a vitimizada "sociedade" é na realidade o algoz desses indivíduos excluídos, marginalizados e estigmatizados seres humanos que outros seres humanos - simplesmente se recusam a "ver".

Manuel Puig e Pedro Lemebel apresentam, em níveis e graus diferentes, a temática homoerótica a partir do ponto de vista interno, ou seja, da vivência homossexual. As oposições podem ser observadas no modo como abordam o tema em suas obras, mais próximos e/ou distantes da questão explicitamente política. A vivência biográfica dos escritores e a experiência da subjetividade homossexual dão lugar a uma observação atenta, que se depara com uma alteridade efetivamente radical, que confronta (e conforta) os leitores com sua própria experiência sexual.

\section{RESUMEN}

El artículo propone un abordaje acerca de la vida y de las obras de los escritores Manuel Puig (Argentina) y Pedro Lemebel (Chile), evidenciando como esos autores crearon sus respectivas narrativas una intensa intersección entre vida y literatura.

\section{PALABRAS-CLAVE}

Manuel Puig, Pedro Lemebel, literatura, América Latina, homo-afectividad

\section{REFERÊNCIAS}

BUTLER, Judtih. Problemas de gênero - feminismo e subversão da identidade. Trad. Renato Aguiar. Rio de Janeiro: Civilização Brasileira, 2003.

FOUCAULT, Michel. História da sexualidade - a vontade de saber. Trad. Maria Thereza da Costa Albuquerque e J. A. Guilhon Albuquerque. São Paulo: Graal, 2005. v. I.

FREUD, Sigmund. Tres ensayos de teoría sexual y otras obras. In: Obras completas. Buenos Aires: Amorrortu Editores, 2001. p 123-134.

LEAL, Juliana. La esquina es mí corazón: espacialidades performáticas nas crônicas de Pedro Lemebel. Dissertação (Mestrado) Belo Horizonte: UFMG, 2007.

LEMEBEL, Pedro. Loco Afán - crónicas de um Sidario. Santiago de Chile: LOM. Ediciones, 1997.

LEMEBEL, Pedro. La esquina es mí corazón. Santiago: Editorial Cuarto Proprio, 1997. LINK, Daniel. Como se lê e outras intervenções críticas. Trad. Jorge Wolff. Chapecó: Argos Editora Universitária, 2002. 
LEMEBEL, Pedro. De perlas y cicatrices - crónicas radicales. Santiago de Chile: LOM Ediciones Ltda., 1998.

LOPES JÚNIOR, Francisco Caetano. A estória da história : questões da crítica cultural em El beso de la Mujer Araña, Stella Manhatan e Balada da praia dos cães. Tese (Doutorado) Rio de Janeiro, Pontifícia Universidade Católica do Rio de Janeiro, 1989.

MARTINEZ, Tomáz Eloy. Manuel: La muerte no es un adiós. La Nación, Buenos Aires, 1997.

NOGUEIRA DA GAMA, Veridiana Fernandes. Manuel Puig e Wong Kar Wai: os imbricamentos do Kitsch e da memória. Dissertação (Mestrado) Belo Horizonte: UFMG, 2006.

PUIG, Manuel. El beso de la Mujer Araña. Buenos Aires: Seix Barral, 1993.

SANTIAGO, Silviano. O cosmopolitismo do pobre. Belo Horizonte: Ed. UFMG, 2004. 